\title{
Conservation of the World's Rarest Tortoise
}

The angonoka (Geocbelone yniphora) is a large ( $45 \mathrm{~cm}$ straight carapace length) tortoise restricted to a patchy habitat of secondary forest and savannas within a $3-\mathrm{km}$ radius of the Bay of Bali in northwestern Madagascar. Its large size, unusual morphology, biogeographical history and rarity combine to make the species scientifically interesting, but its rarity and inaccessibility make it difficult to study. Although no accurate estimate of the total number of angonoka is available (Curl 1986), several censuses have resulted in estimates of some 100 to $\mathbf{4 0 0}$ animals remaining in the wild, with approximately 50 additional individuals kept by private individuals in Madagascar (Juvik et al. 1981, Curl et al. 1985). The International Union for Conservation of $\mathrm{Na}$ ture and Natural Resources (IUCN) lists the angonoka as one of the twelve most threatened animal species in the world (Anonymous 1985), in "imminent danger of extinction" (Groombridge 1982), and it is listed on "Appendix I" by the Convention on International Trade in Endangered Species of Wild Fauna and Flora (CITES). It is legally protected under Malagasy law by the Service des Eaux et Forêts.

\section{Threats}

Historically this species may never have been more widespread nor existed at much higher densities (Juvik \& Blanc 1974, Juvik et al. 1981), but a number of recent human activities may be at least partially responsible for its current situation. For example, around the turn of the century, angonoka were collected for export as a food delicacy (Juvik et al. 1981). Commercial exploitation, however, was apparently short lived, and local inhabitants generally consider consumption of land turtles taboo. The exceedingly low densities of the remaining angonoka populations in the wild may be causing an "Allee effect"- the chances of appropriate individuals finding each other at the proper time may be too low for consistent reproductive success.

More enduring and conspicuous than past exploitation, however, are the effects of anthropogenic fires and introduced African bush pigs (Potamochoerus porcus). Madagascar's savannas are typically burned either annually or more frequently, to improve pasture for cattle. The tortoises usually are not found in the savannas, but occasionally fire spreads into their preferred habitat (Curl et al. 1985). Predation by feral pigs on these tortoises has not been observed, but pigs are common in the angonoka's range, and pig predation on tortoise eggs and young tortoises has been well documented in the Galapagos (MacFarland et al. 1974). Unfortunately, the human inhabitants of the region do not generally hunt or eat pigs.

Although a permit is required legally, throughout their range angonoka are commonly, though covertly, kept as pets by rural inhabitants. Angonoka are captured opportunistically, and usually kept in chicken yards. Tortoises are generally easy to maintain in captivity, and most captive angonoka appear to be in good health (Curl et al. 1985). This captive population could make a significant contribution to future conservation of the species only if further collection is restricted to avoid replacing these captives with additional individuals from the wild.

\section{Early Captive Breeding}

Initial efforts to protect the future of angonoka focused on surveys and captive breeding outside of Madagascar (Juvik et al. 1981). In 1971 six animals were taken from Madagascar to the Honolulu Zoo, which had a history of successes with tortoise breeding (Juvik \& Blanc 1974). Three other angonoka were in captivity elsewhere in the U.S. Only one female ever laid eggs; despite repeated copulations and nesting attempts, only a single offspring was produced by these animals (McKeown et al. 1982), and now only five angonoka (including the hatchling) survive outside of Madagascar.

Reasons for the poor results are unclear, but initial lack of the zoo's commitment to the project, incubator failure, and other inadvertent mortality apparently contributed (Mckeown et al. 1982, S. McKeown, personal communication). Electroejaculation of the single reproductively active male revealed that sperm quality was poor (J. O. Juvik, personal communication); the hatchling that was produced was a result of artificial insemination. Later electroejaculation attempts apparently resulted in the male's death (S. McKeown, personal communication). Currently, the remaining adult male and two adult females are 
housed at the New York Zoological Society's Wildlife Survival Center off coastal Georgia (USA), where one female has been laying infertile eggs regularly. Evidence from other tortoise species suggest that multi-male groups and perhaps male-male combat may be necessary for successful captive breeding.

\section{Current Conservation}

In 1981 the IUCN Tortoise Specialist Group made the angonoka their top research priority, resulting in additional surveys and conservation efforts (Curl et al. 1984, Curl 1986) in cooperation with other organizations, particularly the Jersey Wildlife Preservation Trust (JWPT). Education materials have been prepared and distributed to local inhabitants, and the response has been positive However, the natural history of the species is poorly known. Less than 20 specimens exist in major European or American museums or collections, and no investigators have encountered more than 14 individuals in the field, making intensive research on the species difficult and unpredictable. Future plans are to involve students of the University of Madagascar in basic research (L. Durrell, personal communication).

The Tortoise Specialist Group and the JWPT, in cooperation with the Malagasy Directorate of Waters and Forests, arranged in 1986 to have eight captive angonoka brought together for a captive breeding project at the Ampijoroa Forestry Station, near the range of the species. So far ten hatchlings have been produced, and the information learned sug gests that even greater success can be expected in the future ( $\mathrm{L}$. Durrell, personal communication). Currently JWPT personnel are operating the breeding station; however, a Malagasy employee of the Directorate of Waters and Forests is being trained to take over the entire project. Eventually offspring from this captive breeding program and tortoises obtained from private individ- uals may be used to bolster depleted wild populations and the U.S. breeding program (L. Durrell, personal communication).

Some conservation efforts have been directed towards the objective of providing long term protection in the form of a reserve, especially in an area that may have been depleted by high levels of collection. Cape Sada has been suggested for several reasons: it is infrequently used by local inhabitants and therefore has low economic value, it would be relatively easy to fence off and eliminate pigs inside, and it presently supports a population of angonoka. However, the population is estimated to contain no more than 12 to 15 individuals, and chance events alone would make such a small population unlikely to persist any reasonable time period without repeated introductions. A viable population will probably require more than the $3 \mathrm{~km}^{2}$ of habitat available on Cape Sada. Further, tourism could not be easily promoted in the area to support such a reserve, and thus reintroduction of angonoka to a larger existing reserve that is more accessible seems necessary.

\section{Threats Revisited}

Recent research suggests that anthropogenic fires may not pose a novel threat to angonoka survival. Claims that anthropogenic fires were causing the loss and fragmentation of angonoka's habitat (e.g., Blanc 1972-3, Juvik et al. 1981, Curl et al. 1984) have not been supported by data. Curl et al. (1985) found only very minor differences between vegetation boundaries in the region on 1973 Landsat photographs when compared to 1949 aerial maps and 1958 vegetation maps; apparently habitat patch size and location have changed little. Although burning is common in the region, it is generally not severe along the coastal area inhabited by angonoka, and no dramatic habitat changes were apparent between re- peat visits over several years (Curl 1986). No burned angonoka have been found in the field. In fact, fire may have been a regular component of the environment over much of the angonoka's evolutionary history. Recent evidence suggests that, far from being largely rain forest before human colonization, much of Madagascar was a mosaic of forests and savannas long before humans arrived some 2000 years ago (Burney $1987 a, 1987 b, 1988$ ). Humans may have altered fire frequency and seasonality, apparently long-term climatic change previously influenced the balance between savannas and forests, at least partially through fires.

Other features of the angonoka's habitat may have also misled some investigators. During the wet season, the Bay of Bali region experiences severe downpours, strong winds, and cyclones, all of which make travel very difficult. Therefore, some previous surveys (e.g., Curl et al. 1985) have been made during the dry season, when tortoises are inactive, and perhaps easily overlooked as they shelter in surface litter (Groombridge 1982, D. Reid, personal communication). Further, although they may occasionally wander far into the savannas (Curl et al. 1985), angonoka are found most frequently in or near the thick secondary forest of scrub and bamboo. The results of a recent expedition in which a concerted effort was made to search through the thick, abrasive vegetation suggest that the tortoises may be somewhat more common than previously reported (D. Reid, personal communication). Although no quantitative data are available yet, perhaps previous estimates of population size have been conservative. Juvik et al. (1981) notes that trained dogs were used by turnof-the-century angonoka collectors; similarly trained dogs used by researchers today may likewise yield more tortoises.

The situation of the wild angonoka may be somewhat less pre- 
carious than previously thought, but certainly continued conservation efforts are necessary. Other than the single reproducing captive population, the future for angonoka rests on a small number of individuals scattered at low density in a small area of Madagascar. Evidence from this and other tortoise species suggests that under appropriate conditions, reproductive and recruitment rates can be high. Along with securing the remaining wild population, establishment of at least two captive breeding programs would enable depleted wild populations to be quickly supplemented and greatly improve the odds for persistence of angonoka.

\section{Acknowledgments}

I have both enjoyed and appreciated helpful conversations and correspondence with D. A. Curl, L. Durrell, J. Iaderosa, J. O. Juvik, S. McKeown, and D. Reid. I thank T. Root for editorial assistance.

Russell L. Burke

Department of Biology

University of Michigan

Ann Arbor, MI 48109-1048

\section{Literature Cited}

Burney, D. A. 1987a. Late Quaternary stratigraphic charcoal records from Madagascar. Quaternary Research 28: 274-28.

Burney, D. A. 1987b. Holocene vegetational change in Central Madagascar. Quaternary Research 28:13-143.

Burney, D. A., and R. D. E. MacPhee. 1988. Mysterious island. Natural History July:47-54.

Blanc, C. P. 1972-3. Status survey of Testudo ynipbora. World Wildlife Yearbook 1972-3:93-4.

Curl, D. A. 1986. A recovery plan programme for the Madagascan plowshare tortoise Asterochelys (= Geocbelone) ynipbora Dodo. 23:68-79.

Curl, D. A., I. C. Scoones, M. K. Guy, and G. Rakotoarisoa. 1985. The Madagascan tortoise Geochelone ynipbora: Current status and distribution. Biological Conservation 34:35-54.

Curl, D. A., I. C. Scoones, and M. Guy. 1984. Oxford University Expedition to Madagascar, 1983. Bulletin of the Oxford University Exploration Club (New Series) 7:45-56.

Groombridge, B. 1982. The IUCN amphibia-reptilia red data book, part 1 . IUCN, Gland, Switzerland.

Juvik, J. O., A. J. Andrianarivo, and C. P. Blanc. 1981. The ecology and status of Geochelone yniphora: A critically endangered tortoise in northwestern Madagascar. Biological Conservation 19: 297-316.

Juvik, J. O. and C. P. Blanc. 1974. The angonoka of Cape Sada. Animals 16:148153.

MacFarland, C. G., J. Villa, and B. Toro. 1974. The Galapagos giant tortoises (Geocbelone elepbantopus), Part I: status of the surviving populations. Biolog. ical Conservation 6:118-133.

McKeown, S., J. O. Juvik, and D. E. Meier. 1982. Observations on the reproductive biology of the land tortoises Geochelone emys and Geocbelone yniphora in the Honolulu Zoo. Zoo Biology 1:223-235.

\section{Announcements}

\section{ICBP World Conference}

The International Council for Bird Preservation's World Conference will be held at the University of Waikato Conference Centre, Hamilton, New Zealand, from 21-27 November 1990. The first three days are mainly attended by representatives of ICBP sections, member organizations and specialist groups, but observers may be admitted by application to the ICBP Secretariat. The three days of scientific symposia are open to any participants. Symposium papers are usually published in ICBP technical publications. Symposia topics include: Birds and Tourism, Management Methods for Populations of Threatened Birds, National Bird Conservation Strategies and the Conservation of Biological Diversity, Bird Conservation Problems of the South Pacific Islands. For information, contact ICBP, 32 Cam- bridge Road, Girton, Cambridge, CB3 OPJ, England. (Source: ICBP)

\section{Acid Precipitation Symposium}

On 16-21 September 1990, an international symposium on "Acidic Deposition: Its Nature and Impacts" will be held in Glasgow, Scotland. For details, contact Acidic Deposition 90, CEP Consultants Ltd., 26-28 Albany Street, Edinburgh, EH1 3QH, Scotland. (Source: Acidic Deposition 90)

\section{Wildlife Diseases and Conservation}

The sixth international conference on wildlife diseases and the annual conference of The Wildlife Disease Association will meet together on 6-11 August 1990 in Berlin, German Democratic Republic. The major themes will be effects of pollution on wildlife, introduced diseases and wildlife, and health problem in endangered species. For more information, contact: Torsten Morner, Department of Wildlife Diseases, National Veterinary Institute, P.O. Box 7073, 75007 Uppsala, Sweden. (Source: Wildlife Disease Association)

\section{Second International Congress of Ethnobiology}

This International congress, sponsored by The International Society of Ethnobiology, will be held on 2125 October 1990 in Kunming, China. The congress theme will be challenges of ethnobiology in the 21st century and several symposium will have conservation implications: For more information, contact: Prof. Pei Sheng-ji, Kunming Institute of Botany, Academia Sinica, Heilongtan, Kunming, Yunnan, China. (Source: International Society of Ethnobiology)

\section{World Congress of Landscape Ecology}

The International Association for Landscape Ecology (IALE) will hold a World Congress of Landscape Ecology on 21-25 July 1991 in Ottawa, Canada. The Canadian Society 
for Landscape Ecology and Management, and the U.S. Region of IALE will also hold their annual meetings at the Congress. Eight world-class symposia will address leading topics in landscape ecology in depth. Multiple sessions of contributed papers and posters will cover all active research areas in landscape ecology and management ranging from aesthetics and environmental ethics to spatial flux theory and to management of barriers and corridors. Field excursions will follow July 25 . Contact Gray Merriam, Department of Biology, Carleton University, Ottawa, Canada K1S 5B6, (613)7883859. (Source: IALE)

\section{Biology and Conservation of Epiphytes}

The Marie Selby Botanical Gardens will hold this international symposium on 5-8 May 1991 in Sarasota, Florida. Invited and contributed papers will address: conservation, systematics, ecology, interactions with canopy fauna, physiology, propagation and cultural management. For information, contact: The Marie Selby Botanical Gardens, 811 South Palm Avenue, Sarasota, FL, (813)366-5730. (Source: The Marie Selby Botanical Gardens)

\section{Biotechnology and the Conservation of} Genetic Diversity

On 4-5 September 1990, this international symposium will be held at the Zoological Society of London. The meeting aims to cover ways in which advances in reproductive biology (in vitro egg maturation and fertilization, cryopreservation of spermatozoa and oocytes, rapid diagnostic assays for assessing fertility status, etc.) and molecular genetics (DNA hypervariable sequences, mitochondrial and nuclear DNA polymorphisms) can be applied to species conservation. Speakers include those currently involved in applying these techniques to rare species, as well as scientists developing novel techniques. The symposium will be published by the Zoological Society of London. For further information about the meeting or the publication, contact: Zoological Society of London, Regent's Park, London, NW 1 4RY, England. (Source: Zoological Society of London)

\section{Conservation and Management of Rivers}

This international conference, organized by The Nature Conservancy Council of Great Britain, will be held on 10-13 September 1990 at the University of York in York, England. The focus of the conference will be on habitat and wildlife conservation; topics include: philosophies of conservation, characteristics and classification of river ecosystems, threats to rivers, integration of conservation into other river management objectives, and protecting rivers by legislation. For more information, contact: Dr. P.J. Boon, Nature Conservancy Council, Northminster House, Peterborough PE1 1UA, England. (Source: Nature Conservancy Council)

\section{5th International Congress of Ecology}

The Science Council of Japan and the Ecological Society of Japan will sponsor the 5th International Congress of Ecology in Yokohama City on 23-30 August 1990. Organized by the International Association for Ecology (INTECOL) and the ecology section of the International Union of Biological Sciences (IUBS), the congress will include plenary lectures, symposia, workshops, contributed papers and posters, field trips, advanced courses, and public lectures on the theme "Ecological Perspectives in the 21st Century." For a congress circular, write to Professor Akira Miyawaki, Institute of Environmental Science and Technology, Yokohama National University, 156 Tokiwadai, Hodogaya-ku Yokohama 240, Japan or call (045)332-0975. (Source: INTECOL)

\section{Human Influences on Endangered Wildlife Species in Africa}

This symposium on 3-6 December 1990 in Kampala, Uganda, is the third international symposium sponsored by the Ugandan Institute of Ecology. For more details, contact: Dr. Eric Edroma, P.O. Box 3530, Kampala, Uganda. (Source: Fauna and Flora Preservation Society)

\section{International Congress of Systematic} and Evolutionary Biology

The fourth international congress will be held on 1-7 July 1990 at the University of Maryland in College Park, Maryland. There will be three major themes: evolution in perspective (biodiversity, conservation, biotechnology and global change), tempo and pattern of evolution, and systematics and phylogenetic reconstruction. For further information, contact: Congress Secretary ICSEBIV, Department of Microbiology, University of Maryland, College Park, MD 20742. (Source: ICSEB-IV)

\section{Biodeterioration and Biodegradation}

This eighth international symposium will be held on 26-31 August 1990 in Windsor, Ontario, Canada. For more information, contact: Secretariat-Biodeterioration 8, 10657 Galaxie, Ferndale, Michigan 48220 , (313)544-0042. (Source: Secretariat-Biodeterioration 8)

\section{Association for the Advancement of Industrial Crops}

The Association for the Advancement of Industrial Crops (AAIC) is a recently restructured organization dedicated to encouraging the discovery and utilization of new or little-used agricultural plants that can yield products for industry (e.g., lubricants, waxes, fibers, rubber, specialty chemicals). AAIC publishes a semi-annual journal, El Guayulero, and holds annual meetings; the first was held in 1989. The 1990 meeting will be on 8-12 October 1990 at the University of California-Riverside. For further information about AAIC contact: Himayat Naqvi, Botany and Plant Science, University of California, Riverside, CA 92521, (714)787. 4643. (Source: AAIC) 
Symposium on the Restoration of Stream Habitats

This symposium will be held in conjunction with the 52nd Midwest Fish and Wildlife Conference on 2-5 December 1990 in Minneapolis, MN. Invited papers will cover general theory and principles; contributed papers should focus on applied issues. For more information contact: Randy Sauer, Illinois Department of Conservation, Hazlet State Park, Carlyle, IL 62231 (618594-3627). (Source: 52nd Midwest Fish and Wildlife Conference)

\section{Symposium on Ecological Indicators}

The U.S. Environmental Protection Agency is sponsoring this international symposium on 16-19 October 1990 in Miami, Florida. Topics will include identification, applica- tion, research, and monitoring of ecological indicators that describe the environmental status of estuarine, aquatic, forest, desert, wetland, grassland, and agricultural ecosystems. For further information contact: Janet McDonald, Kilkelly Environmental Associates, P.O. Box 31265, Raleigh, North Carolina 27622 (919-781-3150). (Source: EPA)

\section{Conference on Conservation of Genetic Resources}

An international conference on "Conservation of Genetic Resources for Sustainable Development" will be held on 10-14 September 1990 in Roros, Norway. Hosted by the Norwegian Institute for Nature Research (NINA), the conference aims to describe the state of the art of conservation biology, to clarify central conservation problems and sug. gest research priorities, and to outline how genetic and ecological knowledge can be used in international efforts for sustainable development. For more information, contact: Norwegian Institute for Nature Research, Tungasletta Z, N-7004 Trondheim, Norway (477-913020). (Source: NINA)

\section{Submission of News Items}

Conservation-related news items should be sent to the Associate Editor for International Conservation News, Dr. Stanley A. Temple, Department of Wildlife Ecology, University of Wisconsin, Madison WI 53706, U.S.A. Decisions concerning publication of submitted material rest with the news editor.

COORDINATOR/HAWAII CONSERVATION BIOLOGY INITIATIVE (HCBI). The HCBI has been organized as a cooperative effort between The University of Hawaii and the Nature Conservancy of Hawaii. The Initiative's mission is to guide preserve design and long-term stewardship, and to disseminate this conservation expertise worldwide. As Coordinator, the successful candidate will develop programs, organize and support HCBI cooperating parties, design and monitor research activities, spearhead funding efforts, hire, train, and supervise staff, and initiate further opportunities for related conservation endeavors. Basic Requirements: Demonstrated ability to organize and manage a large, complex project and proven ability to sell an idea or program. A graduate degree in ecology, conservation biology, other natural sciences or resource management. Excellent written and verbal communication skills. A Commitment to the protection of significant natural areas.

Also desired: Familiarity with Hawaiian natural history.

Please send qualifications brief and salary requirements to: Director of Admin., The Nature Conservancy of Hawaii, 1116 Smith St., Honolulu, HI 96817.

Equal Opportunity Employer

\section{NEW ZEALAND UNIVERSITY OF CANTERBURY POST-DOCTORAL FELLOWSHIP SCHOOL OF FORESTRY (CONSERVATION RESEARCH GROUP)}

Applications are invited for a two-year University Grants Committee Post-Doctoral Fellowship to assess the impacts of habitat disruption on the functioning of forest ecosystems and the implications of this for conservation in New Zealand. The successful applicant will collaborate with others in the Conservation Research Group and should have a zoological background, preferably in entomology, and a strong interest in conservation science.

Applicants must be aged 35 years or less and have been awarded, or have qualified for the award of, the degree of Doctor of Philosophy, or a degree equivalent thereto, or who have submitted a thesis for examination. The age limit may be relaxed in special circumstances or in order to avoid hardship to an applicant for a Fellowship.

The emolument for a Fellowship shall be at a rate not exceeding the lowest step of the Lecturer salary scale (NZ\$36,000 per annum).

Enquiries may be directed to Dr David Norton, Conservation Research Group, School of Forestry (Fax 643642 999).

Before submitting a formal written application, candidates are requested to obtain Conditions of Appointment from the undersigned.

Applications, quoting Reference Code C90/04, close on 31 July 1990 and must be addressed to: A. W. Hayward, Registrar, University of Canterbury, Private Bag, Christchurch, New Zealand. 